\title{
Application of smart mosquito monitoring traps for the mosquito forecast systems by Seoul Metropolitan city
}

\author{
Sumi Na and Hoonbok Yi
}

\begin{abstract}
Background: The purpose of this study, mosquito forecast system implemented by Seoul Metropolitan city, was to obtain the mosquito prediction formula by using the mosquito population data and the environmental data of the past.

Results: For this study, the mosquito population data from April 1, 2015, to October 31, 2017, were collected. The mosquito population data were collected from the 50 smart mosquito traps (DMSs), two of which were installed in each district (Korean, gu) in Seoul Metropolitan city since 2015. Environmental factors were collected from the Automatic Weather System (AWS) by the Korea Meteorological Administration. The data of the nearest AWS devices from each DMS were used for the prediction formula analysis. We found out that the environmental factors affecting the mosquito population in Seoul Metropolitan city were the mean temperature and rainfall. We predicted the following equations by the generalized linear model analysis: In(Mosquito population) $=2.519+0.08 \times$ mean temperature $+0.001 \times$ rainfall.
\end{abstract}

Conclusions: We expect that the mosquito forecast system would be used for predicting the mosquito population and to prevent the spread of disease through mosquitoes.

Keywords: Environmental factors, Mosquito, Prediction formula, Seoul Metropolitan city

\section{Background}

Since the Industrial Revolution, humans have overexploited the fossil fuels and it caused the global warming (IPCC 2014). These climate changes are known to affect the composition of the atmosphere and climate variability. The rapid increase of mean temperature in Korea due to global warming may bring unexpected changes and natural disturbances in the biological systems inhabiting Korea. Increases of temperature and precipitation lead to the changes of the ecosystem and the increase of vectorborne diseases. The infectious disease vector is affected by environmental factors, such as temperatures and precipitation. The temperature of Korea has steadily climbed at $2.4{ }^{\circ} \mathrm{C}$ for 100 years, and the distribution area and the

* Correspondence: yih@swu.ac.kr

Department of Bio \& Environmental Technology, Graduate School of Seoul Women's University, Seoul, South Korea upper limit of the vectors increased. According to the Korea Institute for Health and Social Affairs (2010), as the temperature increased by $1^{\circ}$, the rate of malaria mediated by mosquitoes increased by $3.4 \%$.

Mosquito is well known as one of the deadliest disease vectors in the world. Mosquitoes have excellent flexibility in the environment. With the global warming phenomenon, the mosquito population is increasing faster than the rate of development of science in mankind (Khasnis and Nettleman 2005). Mosquitoes have been classified 3500 species worldwide, and 56 species have been recorded in Korea (Korea Centers for Disease Control and Prevention. 2014; Fang 2010).

Nowadays, due to increasing temperatures and environmental changes caused by global warming, the period of activity and habitat of mosquitoes is getting wider and gaining more attention as hygienic insect (Lee 2000).

(c) The Author(s). 2020 Open Access This article is licensed under a Creative Commons Attribution 4.0 International License, which permits use, sharing, adaptation, distribution and reproduction in any medium or format, as long as you give appropriate credit to the original author(s) and the source, provide a link to the Creative Commons licence, and indicate if changes were made. The images or other third party material in this article are included in the article's Creative Commons licence, unless indicated otherwise in a credit line to the material. If material is not included in the article's Creative Commons licence and your intended use is not permitted by statutory regulation or exceeds the permitted use, you will need to obtain permission directly from the copyright holder. To view a copy of this licence, visit http://creativecommons.org/licenses/by/4.0/. 


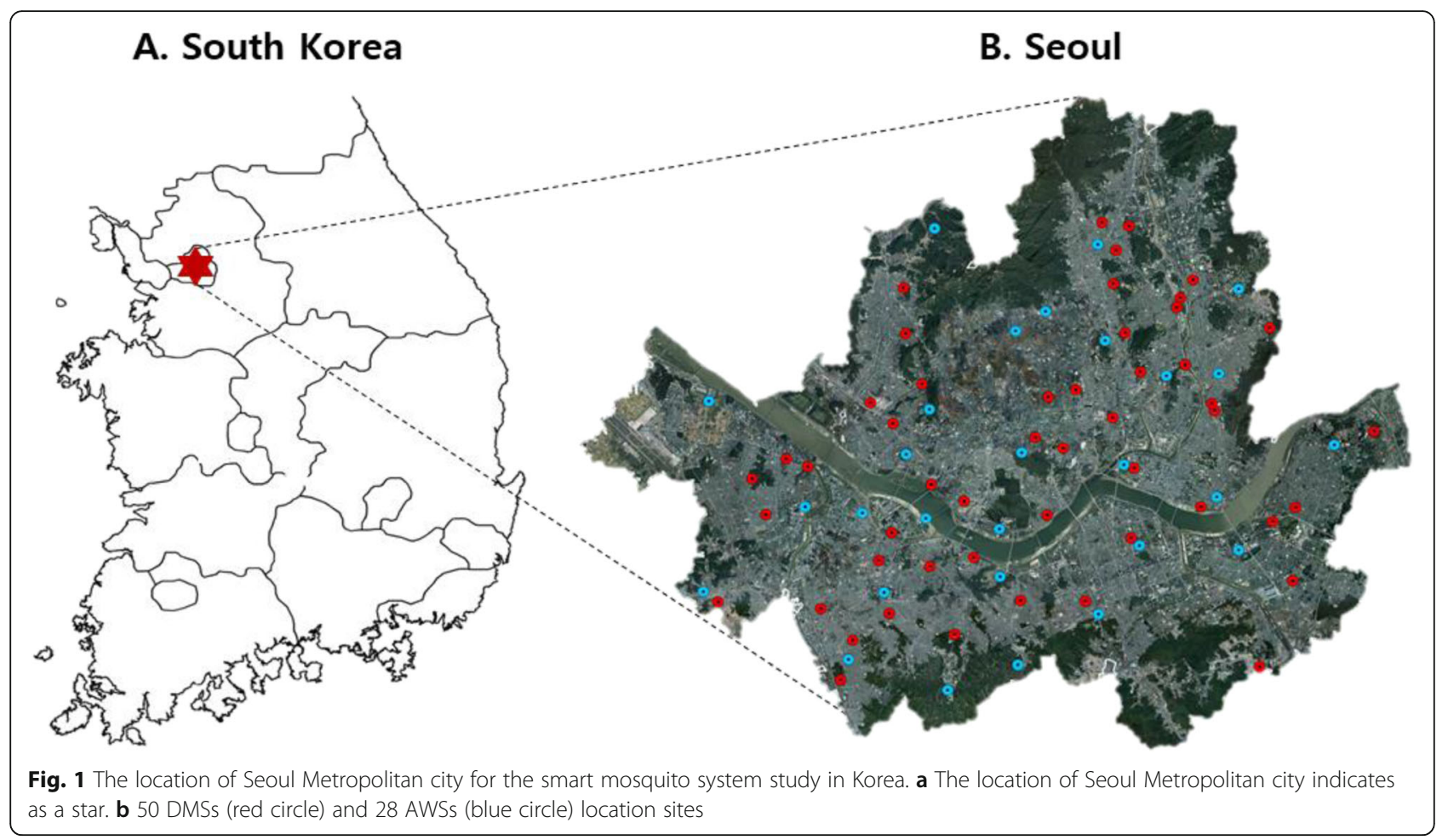

Recently, the population of mosquitoes has increased, and the increase of such disease vectors has led to higher rates of human diseases such as malaria and Japanese encephalitis (Health Insurance Review and Assessment Agency 2016). More than half of the world's population live in areas where mosquitoes infect Zika virus, Dengue fever, Chikungunya fever, and Yellow fever. There are already millions of deaths due to mosquito diseases annually (World Health Organization 2017).
The mosquito-borne diseases are highly affected by climate change and are known to be particularly affected by temperature, precipitation, and humidity (Yi et al. 2014b). With the rising temperature, digestion amount and nutrition supply of larvae increase, and it shorten larvae's growth period (Gillies 1953; Githeko et al. 2000; $\mathrm{Na}$ et al. 2018). This increases the rate at which mosquitoes become adults, and the frequency of bloodsucking by female mosquitoes is increased. As the number of

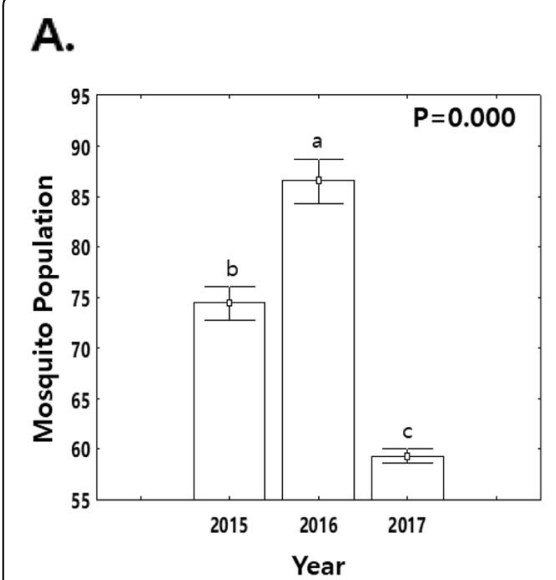

B.

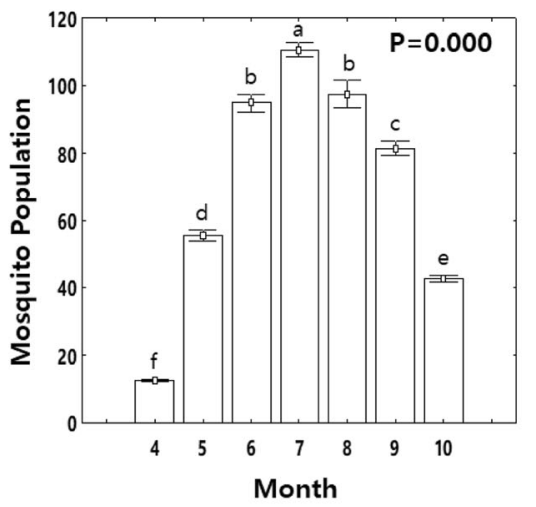

C.

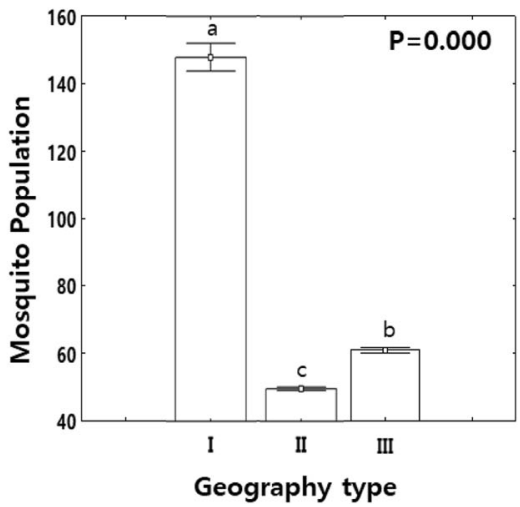

Fig. 2 The average number of mosquito population in Seoul Metropolitan city from 2015 to 2017. a The average number of mosquito population per year. $\mathbf{b}$ The average number of mosquito population per month. c The average number of mosquito population per geography type (I: waterside area, II: residence area, III: park area). The different alphabetical letters on each graph bar mean the statistically significance at each box 
eggs increases, the number of mosquitoes increases (Reisen et al. 1995; Mitchel 1988). As the global warming accelerates, the number of mosquito population and the incidence of diseases due to mosquito-borne diseases rise, so research on mosquito control and population monitoring is urgently required (Khasnis and Nettleman 2005; Xue et al. 2015; Yi et al. 2014a).

This study was carried out with the mosquito forecasting project in Seoul Metropolitan city. The mosquito forecast system is to let Seoul Metropolitan city citizens know the mosquito index for the possibility of mosquito occurrence as four steps: safety, concern, attention, and danger. Seoul Metropolitan city also suggested the citizens' behavior tips according to the four steps of the mosquito occurrence. The mosquito forecast system is continuously operated to protect the health of the Seoul Metropolitan city citizens, and its accuracy is improved by modifying the statistical prediction formula every year. Since Seoul Metropolitan city has the largest number of citizens in South Korea, even though the mosquito forecast system is still a fundamental step, its potential is very important for human health.

The purpose of this study was to obtain the mosquito prediction formula by using the mosquito population data and the environmental data during the past 3 years. We expect that mosquito prediction formula will also support the study on the reduction of disease through mosquitoes.

\section{Methods}

\section{Study sites}

All of the study sites were in Seoul Metropolitan city, where it is the capital of South Korea (Fig. 1a). Seoul Metropolitan city has an area of $605.25 \mathrm{~km}^{2}$ and consists of 25 districts (Korean, gu). The population size in Seoul Metropolitan city is about 9,736,962 as of 2020 (KOSIS 2018, http://kosis.kr/statHtml/statHtml.do?orgId=101 \&tblId=DT_1B040A3\&checkFlag=N).

\section{Collecting mosquito population data and environmental factor data \\ Digital Mosquito Monitoring System}

DMS is an abbreviation of the Digital Mosquito Monitoring System. The DMS consists of steel, PVC, and acrylic (high strength coating), $1080 \mathrm{~mm}$ high, $560 \mathrm{~mm}$ wide, and 320 $\mathrm{mm}$ in diameter, and it is consuming $30 \mathrm{~W} / \mathrm{h}$. DMS also releases $\mathrm{CO}$ at a rate of $300 \mathrm{~mL} / \mathrm{min}$, which is based on the human's breathing amount. The DMS can automatically count the number of captured mosquitoes and transmit data via the CDMA communication module. This information allows mosquito control offices to control mosquitoes more efficiently and eco-friendly. It can also help manage disease by capturing mosquitoes and reducing the number of mosquitoes. Therefore, it can be applied in various environmental and geographical conditions, and the efficiency of the mosquito control system can be improved.

\section{Collecting mosquito population data from DMS}

DMS was operated to monitor the mosquito population. The DMS operation location is shown in Fig. 1b. The mosquito population data and instrument installation location data were collected at the digital mosquito information monitoring system site (ETND 2018, http://dmsnet.kr). Seoul Metropolitan city has installed two DMSs in each district (gu) since 2015 and is currently operating 50 DMSs. For this study, mosquito population data from April 1, 2015, to October 31, 2017, were collected.

\section{Environmental factor data provided by the Korea meteorological administration}

The (Meteorological agency weather data release portal. (n.d.); 2018) provides the weather data, and the KMA uses various devices such as Automatic Weather System (AWS), Automated Surface Observing System (ASOS), and agricultural weather observation (http://data.kma.go. $\mathrm{kr} / \mathrm{cmmn} /$ main.do).

The data of the nearest AWS devices from each DMS were used for the prediction formula analysis. The locations of the linked DMS and AWS were shown in Additional file 1 . This study used data of 23 AWSs out of 28 AWSs in Seoul Metropolitan city from March 28, 2015, to October 28, 2017. According to the results of previous studies of this study, the number of mosquitoes 3 days ago showed the highest correlation with environmental factors. It is the reason why the DMS collection date and the AWS environmental factor date shows a 3-day difference.

\section{The monitoring analysis for mosquito population data and environmental factor data}

The average number of mosquito population per year, the average number of mosquito population per month, the average number of mosquito population per geography type, and the average number of mosquito population per district (gu) were derived by using the mosquito population data from 2015 to 2017. The geography type was divided into three parts. The divided types were as follows. Type I: waterside area, type II: residence area, and type III: park area. Waterside and rainwater pumping stations were included in type I. Residence areas, community service center, physical education center, public health center, apartments, daycare center, and welfare center were included in type II. Parks and forests were included in type III. The mean and standard error were derived for each analysis and used for ANOVA.

The generalized linear model was used for the analysis of the mosquito population data and the environmental factor data from 2015 to 2017 in Seoul Metropolitan city. For all data analysis, the natural log was applied to convert mosquito population data. 
Table 1 The average number of mosquito population in Seoul Metropolitan city from 2015 to 2017 (geography type I: waterside area, II: residence area, III: park area)

\begin{tabular}{|c|c|c|c|c|c|c|c|c|c|}
\hline \multirow[b]{2}{*}{ Year (2015-2017) } & \multicolumn{8}{|c|}{ Mosquito population (mean $\pm \mathrm{SE}$ ) } & \multirow[t]{2}{*}{$p$ value } \\
\hline & \multicolumn{2}{|c|}{2015} & \multicolumn{2}{|c|}{2016} & \multicolumn{3}{|c|}{2017} & All sites & \\
\hline & \multicolumn{2}{|c|}{$74.46 \pm 1.74$} & \multicolumn{2}{|c|}{$86.53 \pm 2.31$} & \multicolumn{3}{|c|}{$59.34 \pm 0.77$} & $73.03 \pm 0.98$ & $0.000^{*}$ \\
\hline & 4 & 5 & 6 & 7 & 8 & 9 & 10 & & $0.000^{*}$ \\
\hline Month & $12.65 \pm 0.32$ & $55.63 \pm 1.68$ & $94.88 \pm 2.76$ & $110.76 \pm 2.39$ & $97.63 \pm 4.36$ & $81.28 \pm 2.14$ & $42.59 \pm 1.03$ & & \\
\hline \multirow[t]{2}{*}{ Geography type } & \multicolumn{2}{|c|}{1} & \multicolumn{2}{|c|}{ II } & \multicolumn{3}{|c|}{ III } & & $0.000^{*}$ \\
\hline & \multicolumn{2}{|c|}{$148.01 \pm 4.33$} & \multicolumn{2}{|c|}{$49.66 \pm 0.53$} & & $60.84 \pm 0.93$ & & & \\
\hline
\end{tabular}

*Significant at $p \leq 0.001$

\section{Derived from mosquito prediction formula in Seoul Metropolitan city}

The mosquito prediction formula of Seoul Metropolitan city was derived by linking the mosquito population data and the environmental factor data from 2015 to 2017.
Before mosquito prediction formula analysis, the mosquito data were transformed to log values.

Mosquito prediction formula accuracy was tested to compare the accuracy between actual and predicted values by using the actual numbers of mosquito

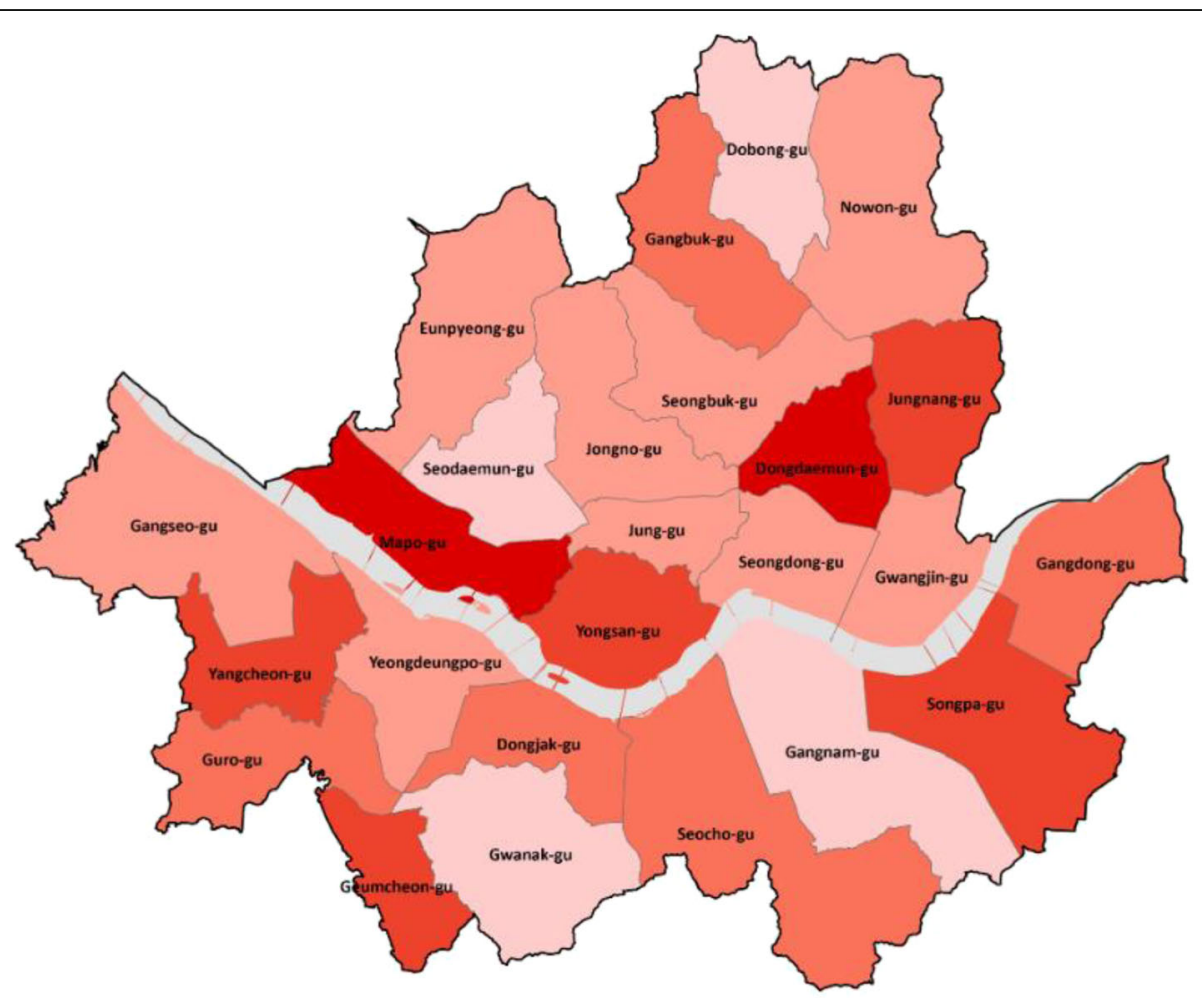

Mosquito Occurrence

Mosquitoes average

2015 - 2017
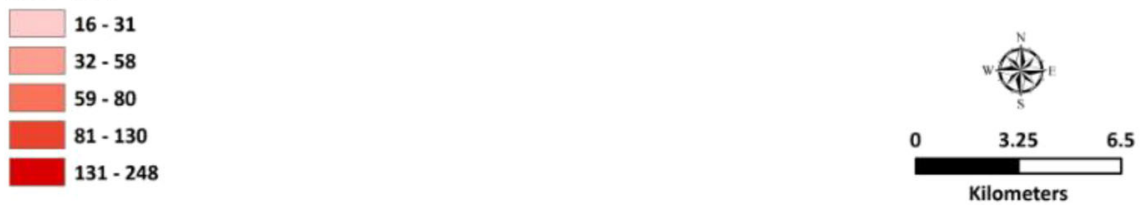

Fig. 3 The average number of mosquito population per district (gu) in Seoul Metropolitan city from 2015 to 2017 
populations collected in 2017 and the predicted values derived from the mosquito population prediction formula.

\section{Results}

\section{Monitoring analysis of mosquito population data}

The results of the average number of the mosquito population per day from 2015 to 2017 were $73.03 \pm$ 0.98 population in Seoul Metropolitan city. The average number of the mosquito population analysis per year was shown in Fig. 2a and Table 1. The largest number of the mosquito population was 2016.

The results of the average number of the mosquito population analysis per month were shown in Fig. 2b and Table 1. The number of mosquito populations sharply increased in June, and the largest number of mosquitoes was collected in July. After July, the mosquito population sharply decreased.

The average numbers of the mosquito population analysis per geography type were as shown in Fig. 2c and Table 1. Mosquito populations were highest in the order of waterside area, park area, and residence area.

The average numbers of the mosquito population analysis in Seoul Metropolitan city from 2015 to 2017 were as shown in Fig. 3. Mosquito population of Mapo, Dongdaemun, and Yangcheon were the highest. However, the mosquito population in Dobong, Gwanak, and Gangnam were the lowest.

\section{Monitoring analysis of environmental factor data}

The results of linear regression analysis of the mosquito population according to environmental factors of Seoul Metropolitan city was shown in the following Fig. 4.

Mean temperature, low temperature, high temperature, rainfall, mean wind speed, and high wind speed showed $0.0001 p$ value. Among them, the mean temperature was selected as a representative factor of temperature. In the case of mean wind speed and maximum wind speed, they were excluded due to high $p$ value. As a result, the mean temperature and rainfall were derived as environmental factors representing the mosquito population.

The result of linear regression analysis of mosquito population according to geography type (I: waterside area, II: residence area, III: park area) per environmental factors in Seoul Metropolitan city was shown in Fig. 5a, b. Linear regression analysis of mosquito population according to geography type per environmental factors showed that the correlation was not high but there was a tendency.

\section{Derivation and accuracy estimation of mosquito prediction formula of Seoul Metropolitan city}

As a result of the generalized linear model analysis of mosquito population in 2015-2017, the following equation was derived (Table 2).

The result of the accuracy of mosquito population prediction formula and mosquito prediction formula by geography type is as follows (Fig. 6). For all tests, the prediction formula was found to be highly relevant.
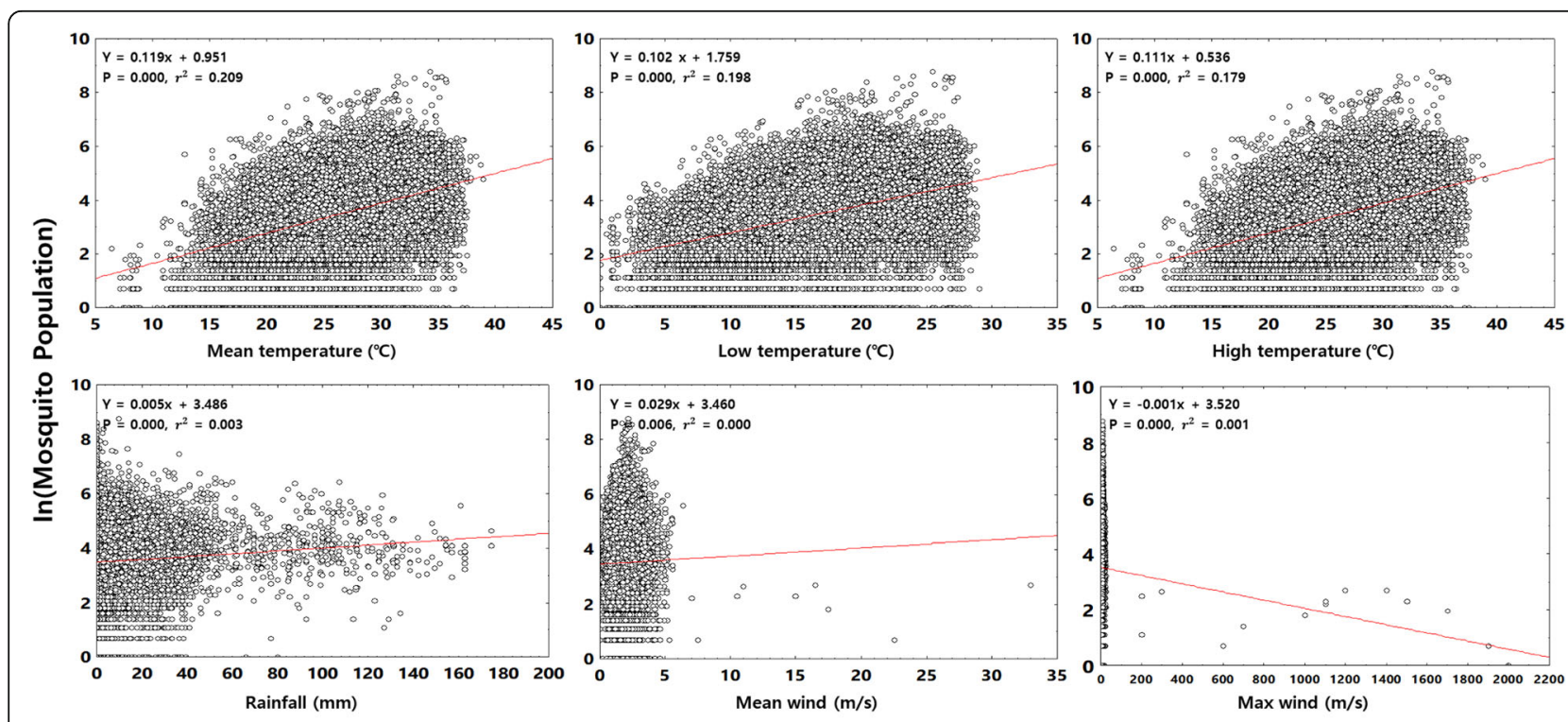

Environmental factors

Fig. 4 The distribution of mosquito population according to environmental factors in Seoul Metropolitan city from 2015 to 2017 . The regression equation and $p$ value and $r^{2}$ were derived through simple linear regression analysis 

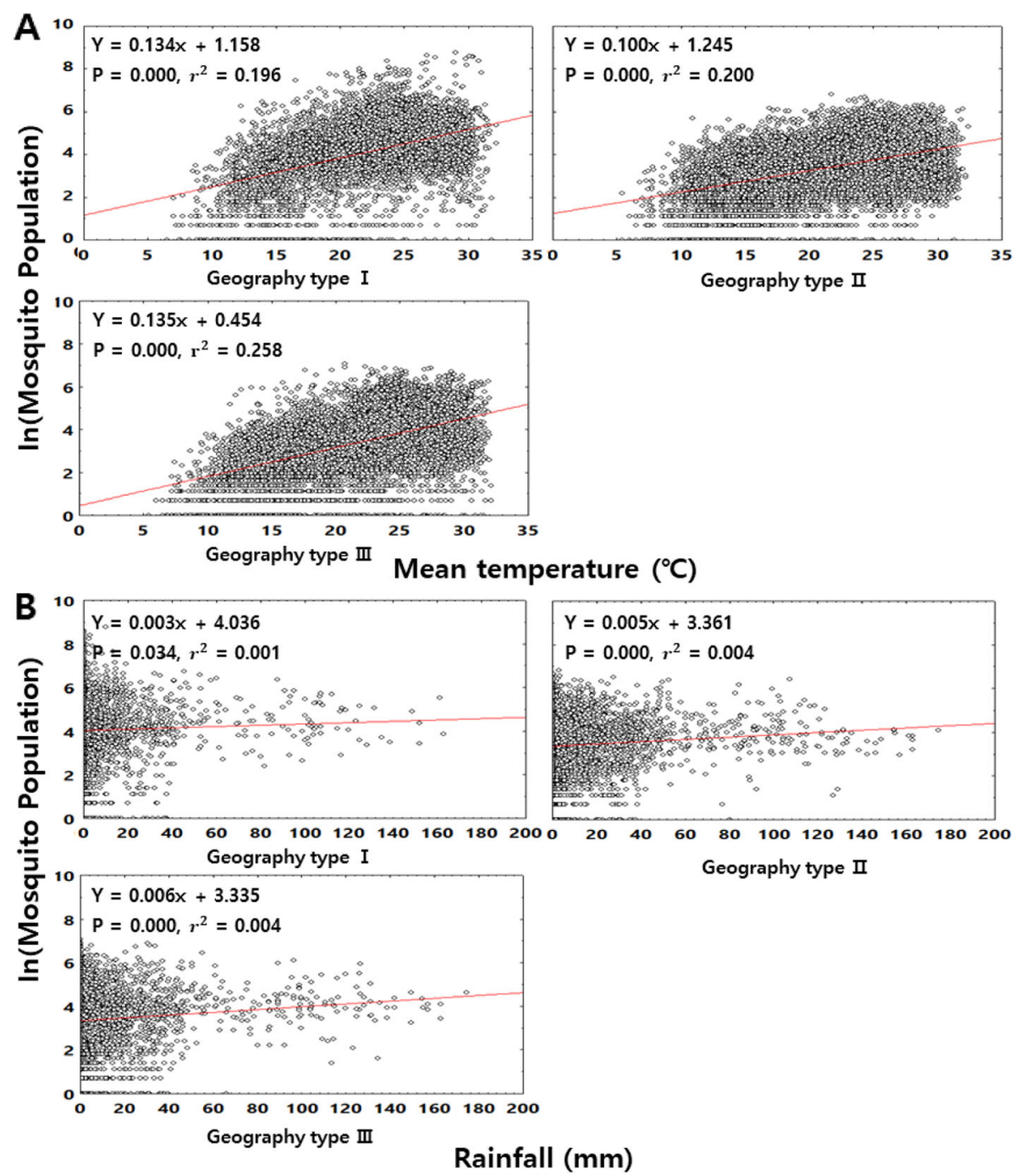

Fig. 5 The distribution of mosquito population according to mean temperature, rainfall in Seoul Metropolitan city from 2015 to 2017 (geography type I: waterside area, II: residence area, III: park area). The regression equation and $p$ value and $r^{2}$ were derived through a simple linear regression analysis. a Mosquito population according to geography type by mean temperature. b Mosquito population according to geography type by rainfall

\section{Discussion}

Mosquitoes are sensitive to environmental factors. Excessive heat kills insects as effectively as cold does. Nevertheless, within their survivable range of temperatures, mosquitoes proliferate faster and bite more as the air becomes warmer. At the same time, greater heat speeds the rate at which pathogens inside them reproduce and mature (Epstein 2000). Therefore, the mosquito population management is urgent, and environmental factors can be analyzed to estimate the mosquito population.

The purpose of this study was to predict the mosquito population in Seoul Metropolitan city by deriving the mosquito population prediction formula. Furthermore, this prediction formula was intended to be used as a basis for predicting the occurrence of disease-mediated mosquitoes.
The results of the average number of the mosquito population per day from 2015 to 2017 were $73.03 \pm 0.98$ population in Seoul Metropolitan city. The number of mosquito populations sharply increased in June, and the largest number of mosquitoes was collected in July. Since the mosquito population significantly decreases after July, in order to control mosquito effectively, it is necessary to intensively control larvae in May. Also, as the mosquito species in June-July surges, it is better to do chemical control in parallel.

As a result of the mosquito population analysis by geography type, the mosquito population was found to be higher in the order of the waterside area, residence area, and park area. It is predicted that mosquito populations are large in the waterside area and park area where it is suitable for larvae, so mosquito control should be concentrated around the riverside and park area. 
Table 2 Generalized linear model formula of mosquito population in Seoul Metropolitan city from 2015 to 2017 (geography type I: waterside area, II: residence area, III: park area)

\begin{tabular}{|c|c|c|}
\hline Mosquito population prediction formula & $\begin{array}{l}\text { Geography } \\
\text { type }\end{array}$ & Mosquito population prediction formula \\
\hline \multirow[t]{3}{*}{$\begin{array}{c}\text { In }(\text { Mosquito population })=2.519+0.08 \times \text { mean temperature }+0.001 \times \\
\text { rainfall }\end{array}$} & 1 & $\ln ($ Mosquito population $)=3.184+0.084 \times$ mean temperature $-0.004 \times$ \\
\hline & II & $\ln ($ Mosquito population $)=\underset{\text { rainfall }}{2.489}+0.065 \times$ mean temperature $+0.003 \times$ \\
\hline & III & $\ln ($ Mosquito population $)=\underset{\text { rainfall }}{2.128}+0.089 \times$ mean temperature $+0.002 \times$ \\
\hline
\end{tabular}

As a result of the linear regression analysis of the mosquito population in Seoul Metropolitan city, the mean temperature and rainfall were derived as environmental factors representing the mosquito population. Rainfall was used in this analysis since rainfall can be the most important factor in providing larval habitat.

By matching the mosquito population data and environmental factor data from 2015 to 2017, the generalized linear model analysis was conducted and the

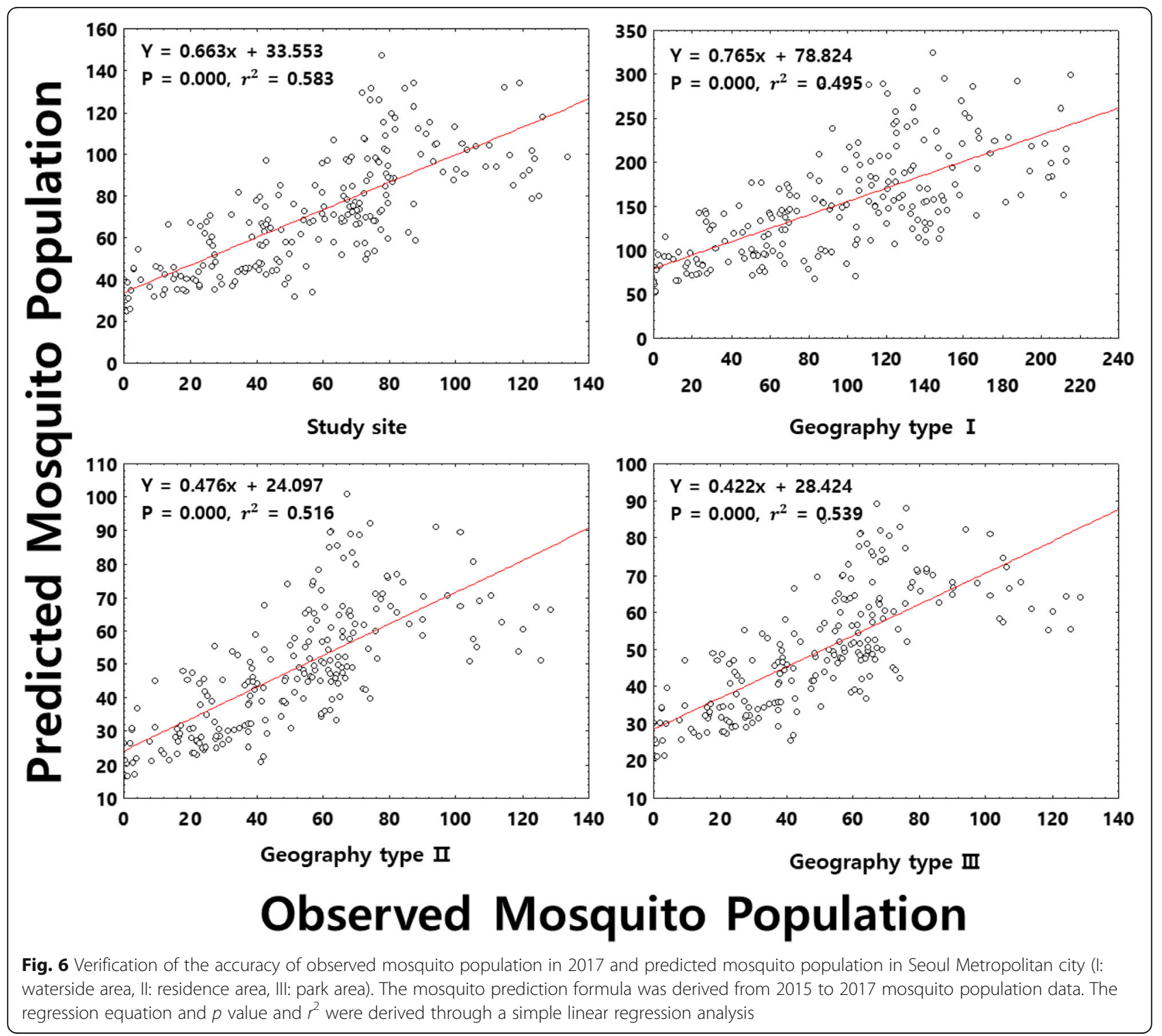


mosquito population prediction formula with high accuracy was gained.

\section{Conclusion}

This study will have a positive effect if the mosquito control is carried out at the appropriate time using the mosquito population prediction formula. In conclusion, we hope that the mosquito forecasting system in Seoul Metropolitan city control the spread of mosquito-borne diseases, reduce the damage from mosquito, and protect the well-being of citizens in Seoul Metropolitan city.

\section{Supplementary information}

Supplementary information accompanies this paper at https://doi.org/10. 1186/s41610-020-00155-w.

Additional file 1. Linked DMS and AWS. The nearest AWS devices from each DMS were used for the prediction formula analysis (geography type: I: waterside area, II: residence area, III: park area).

\section{Abbreviations}

ASOS: Automated Surface Observing System; AWS: Automatic Weather System; DMS: Digital Mosquito Monitoring System; KMA: Korea Meteorological Administration

\section{Acknowledgements}

We thank the Seoul Metropolitan Government. And the project was conducted through the Seoul Mosquito Forecasting Service Project.

\section{Authors' contributions}

SMN observed and analyzed the mosquito population data and environmental data to derive the mosquito population prediction formula. $\mathrm{HBY}$ interpreted the data set and was a major contributor in writing the manuscript. The authors read and approved the final manuscript.

\section{Funding}

The project was supported by the 2018 Seoul Mosquito Forecasting Service Project through the Seoul Metropolitan Government.

\section{Availability of data and materials}

The datasets used and/or analyzed during the current study are available from the corresponding author (Dr. Hoonbok Yi, yih@swu.ac.kr) on reasonable request.

\section{Ethics approval and consent to participate}

Not applicable.

\section{Consent for publication}

Not applicable.

\section{Competing interests}

The authors declare that they have no competing interests.

Received: 23 April 2019 Accepted: 14 April 2020

Published online: 18 June 2020

\section{References}

Epstein PR. Is global warming harmful to health? Scientific American. 2000;283(2): 50-7.

ETND (n.d.). Digital Mosquito Information Monitoring System; 2018. http:// dmsnet.kr/.

Fang J. Ecology: a world without mosquitoes. Nature News. 2010;466(7305):432-

Gillies MT. The duration of the gonotrophic cycle in Anopheles gambiae and Anopheles funestus, with a note on the efficiency of hand catching. East Afr Med J. 1953;30(4):129-35.
Githeko AK, Lindsay SW, Confalonieri UE, Patz JA. Climate change and vectorborne diseases: a regional analysis. Bull World Health Organ. 2000;78:113647.

Health Insurance Review and Assessment Agency. Attention to mosquito-borne infectious diseases such as malaria and dengue in summer; 2016.

IPCC. Fifth Assessment Report; 2014.

Khasnis AA, Nettleman MD. Global warming and infectious disease. Arch Med Res. 2005:36(6):689-96.

Korea Centers for Disease Control and Prevention. Guidelines for management of major infectious disease-related mosquito control; 2014.

Korea Institute for Health and Social Affairs. Climate change and health adaptation measures; 2010.

KOSIS, (n.d.); 2018. http://kosis.kr/statHtml/statHtml.do?orgld=101\&tblld=DT_1B04 $0 A 3 \&$ checkFlag $=\mathrm{N}$.

Lee DK. Effective methods and management for mosquito control by local health centers. Kosin J Health Sci. 2000;10:117-24.

Meteorological agency weather data release portal. (n.d.); 2018. https://data.kma. go. $\mathrm{kr} / \mathrm{cmmn} / \mathrm{main}$.do.

Mitchel CJ. Occurrence, biology, and physiology of diapause in overwintering mosquitoes. Arboviruses. 1988;1:191-218.

Na SM, Jang HJ, Park SJ, Lee EY, Doh JS, Hong SB, Yi HB. The effect of four different temperatures on the growth of Aedes albopictus larva. J Wetlands Res. 2018;20(2):155-60.

Reisen WK, Lothrop HD, Hardy JL. Bionomics of Culex tarsalis (Diptera: Culicidae) in relation to arbovirus transmission in southeastern California. J Med Entomol. 1995:32(3):316-27.

World Health Organization. http://www.who.int/csr/disease/zika/en/. 2017.

Xue RD, Smith ML, Yi HB, Kline DL. Field evaluation of a novel Mos-Hole trap and naphtha compared with BG sentinel trap and mosquito magnet $X$ trap to collect adult mosquitoes. J Am Mosq Control Assoc. 2015;31(1):110-2.

Yi HB, Devkota BR, Yu JS, Kim HJ. A research for an eco-friendly mosquito control by using a new mosquito trap (Mos-hole trap) in a cowshed in Yeoju of Korea. Anim Cells Syst. 2014a;18(4):282-90.

Yi HB, Devkota BR, Yu JS, Oh KC, Kim JH, Kim HJ. Effects of global warming on mosquitoes \& mosquito-borne diseases and the new strategies for mosquito control. Entomol Res. 2014b;44(6):215-35.

\section{Publisher's Note}

Springer Nature remains neutral with regard to jurisdictional claims in published maps and institutional affiliations.
Ready to submit your research? Choose BMC and benefit from:
- fast, convenient online submission
- thorough peer review by experienced researchers in your field
- rapid publication on acceptance
- support for research data, including large and complex data types
- gold Open Access which fosters wider collaboration and increased citations
- maximum visibility for your research: over $100 \mathrm{M}$ website views per year
At BMC, research is always in progress.
Learn more biomedcentral.com/submissions 